http:/ / dx.doi.org/10.21707/gs.v11.n04a08

\title{
EFEITO DO ESTRESSE SALINO NA GERMINAÇÃO E CRESCIMENTO INICIAL de Plântulas de ERYTHRina VElutina Willd. (Fabaceae)
}

\author{
Renata Conduru Ribeiro ${ }^{1 *}$, Bárbara França Dantas ${ }^{1}$, Janete Rodrigues Matias ${ }^{1}$, Claudinéia Regina \\ Pelacani $^{2}$
}

${ }^{1}$ Laboratório de Análise de Sementes, Embrapa Semiárido, Rodovia BR-428, Km 152, Zona Rural - Caixa Postal 23, Petrolina, Pernambuco, Brasil. CEP: $56302-970$

${ }^{2}$ Laboratório de Germinação, Unidade Experimental Horto Florestal, Departamento de Biologia, Universidade Estadual de Feira de Santana, Feira de Santana, Babia, Brasil.

*Autor para correspondência: rconduru@gmail.com

Recebido em 05 de janeiro de 2017. Aceito em 30 de julho de 2017. Publicado em 30 de dezembro de 2017.

REsumo - O objetivo deste trabalho foi avaliar o efeito do estresse salino sobre o crescimento plântulas de Erythrina velutina Willd. (Fabaceae). As sementes de mulungu foram colocadas para germinar em solução de $\mathrm{NaCl}$ preparada em diferentes condutividades elétricas (CE): 0, 4, 6, 8 e 12 dS.m $\mathrm{m}^{-1}$, durante 16 dias. Além do número de sementes germinadas (\%), foram analisadas: comprimento, a massa fresca e seca da parte aérea e da raiz primária das plântulas. A massa seca da parte aérea e raiz foi posteriormente utilizada para extração e quantificação dos açúcares solúveis totais (AST); açúcares redutores (AR); sacarose (SAC); proteínas solúveis (PT) e aminoácidos totais (AA). A germinação das sementes de E. velutina não foi afetada pelo tratamento de simulação de estresse salino e o crescimento de plântulas foi afetado negativamente após 16 dias de estresse. Soluções de maior CE foram capazes de reduzir a produção de massa seca proporcionando diminuição da razão parte aérea/raiz de E. velutina. A restrição hídrica promovida pelo sal provocou uma desaceleração dos processos fisiológicos e bioquímicos durante a germinação. Esta espécie provavelmente não suporta crescer em solos com potencial osmotico superior a $6 \mathrm{dS} \cdot \mathrm{m}^{-1} \mathrm{CE}$.

Palavras chave: CaAtinga; Macromoléculas; Salinidade; Vigor.

EFFECT OF SALT STRESS ON GERMiNATION AND INITIAL GROWTH OF ERYTHRINA VELUTINA WiLld. (FABACEAE) SEEDLingS

Aвstract - The objective of this study was to evaluate the effect of salinity on growth of Erythrina velutina Willd. (Fabaceae) seedlings. Mulungu seeds were germinated in $\mathrm{NaCl}$ solution prepared in different electrical conductivity (EC): 0, 4, 6, 8 and $12 \mathrm{dS} . \mathrm{m}^{-1}$ for 16 days. Besides the number of germinated seeds (\%), were analyzed: total length, fresh and dry weight of shoot and primary root. The dry weight of shoot and root was subsequently used for extraction and quantification of soluble sugars (AST), sugars (RS), sucrose (SAC), soluble proteins (TP) and total amino acids (AA). The germination of mulungu was not affected by simulation of salt stress, differently from results of seedlings development. Solutions of higher EC were able to reduce the production of dry mass providing lower shoot/root of E. velutina seedlings. The water restriction promoted by salt caused a slowing of physiological and biochemical processes during germination. This specie probably does not support grow on osmotic potential exceeding $6 \mathrm{dS} \cdot \mathrm{m}^{-1}$.

Keywords: CAATINGA; MACROMOLECULES; S ALINITY; VigOR.

EFECTO DEL ESTRÉS SALINO EN LA GERMINACIÓN Y EN EL CRECIMIENTO INICIAL DE PLÁNTULAS DE ERYTHRINA VELUTINA Willd. (FABAcEae) 
REsumen - Se objetivó evaluar el efecto del estrés salino sobre el crecimiento de las plántulas de Erythrina velutina Willd. (Fabaceae). Se colocaron las semillas de mulungu para germinar en solución de $\mathrm{NaCl}$ preparada en diferentes conductividades eléctricas (CE): 0, 4, 6, 8 y 12 dS.m.-1 durante 16 días. Además del número de semillas germinadas (\%), se analizaron: longitud, masa fresca y seca de la parte aérea y de la raíz primaria de las plántulas. La masa seca de la parte aérea y de la raíz fue posteriormente utilizada para extracción y cuantificación de los azúcares solubles totales (AST), azúcares reductores (AR), sacarosa (SAC), proteínas solubles (PT) y aminoácidos totales (AA). La germinación de las semillas de E. velutina no fue afectada por el tratamiento de simulación de estrés salino y el crecimiento de plántulas fue afectado negativamente después de 16 días de estrés. Las soluciones de mayor CE fueron capaces de reducir la producción de masa seca proporcionando disminución de la razón parte aérea / raíz de E. velutina. La restricción hídrica promovida por la sal provocó una desaceleración de los procesos fisiológicos y bioquímicos durante la germinación. Es probable que esta especie no crezca en suelos con un potencial osmotico superior a $6 \mathrm{dS} \cdot \mathrm{m}^{-1} \mathrm{CE}$.

Palabras clave: CaAtinga; Macromoléculas; Salinidad; Vigor.

\section{INTRODUÇÃO}

A salinização dos solos é um sério problema mundial, pois tem limitado substancialmente a produção agrícola, esse problema é mais agudo nas regiões semiáridas onde a baixa pluviosidade e a elevada demanda evaporativa contribuem decisivamente para o agravamento da salinização dos solos (Viégas et al. 2001, Sairam e Tyagi 2004). Essas condições prevalecentes na região semiárida do Nordeste brasileiro demonstram a necessidade de serem desenvolvidos trabalhos objetivando o aproveitamento de seus recursos naturais, notadamente aqueles relacionados com o nível de tolerância da espécie a essas condições adversas, como no caso da salinidade dos solos.

As espécies nativas do bioma Caatinga são adaptadas às severas condições climáticas predominantes na região, podendo constituir uma importante alternativa para o aproveitamento e recuperação das áreas salinizadas ou em processos de salinização, condições em que a exploração de muitas espécies agrícolas é inviável economicamente (Silva et al. 2009).

O mulungu (Erythrina velutina Willd.) é uma leguminosa nativa da Caatinga, propagada principalmente por sementes e que apresenta relevante importância econômica e medicinal (Lorenzi e Matos 2002, Carvalho, 2008). Infelizmente, essa espécie ainda é pouco estudada nos diversos aspectos agronômicos, especialmente em condições de estresse salino.

O período germinativo é importante para a sobrevivência das espécies florestais, principalmente em locais onde a disponibilidade de água é limitada, como a Caatinga (Braga et al. 2009). Para que as sementes germinem é necessário que existam condições favoráveis de luz, temperatura e disponibilidade de água (Carvalho e Nakagawa 2012). O processo germinativo se inicia com a absorção de água por embebição, porém, o excesso de sal no substrato causa restrição da absorção de água pelas sementes, devido à diminuição do potencial osmótico do mesmo (Chaves et al. 2009). Isso retarda a embebição das sementes ou o alongamento da raiz, além de provocar toxicidade nos tecidos devido ao acúmulo em excesso dos íons Na+ e Cl- (Esteves e Suzuki 2008, Góis et al. 2008). Assim como a inibição, em parte ou total, da germinação de sementes, a inibição do crescimento das plantas sob salinidade ocorre por duas razões. A primeira é devido ao efeito osmótico ou déficit hídrico provocado pela salinidade, que reduz a absorção de água. A segunda é devido ao efeito específico dos íons ou excesso de íons, que entram no fluxo de transpiração e eventualmente causam injúrias nas folhas, reduzindo 
assim o crescimento (Munns 2005).

Os níveis de tolerância às concentrações de sais letais são diferenciados nas plantas, utilizando-se de uma variedade de mecanismos entre as distintas espécies. A tolerância à salinidade é a capacidade das plantas de desenvolverem e completarem seu ciclo de vida sobre um substrato que contém elevada concentração de sais solúveis (Flowers et al. 1977, Greenway e Munns 1980). Além disso, as plantas podem se comportar de forma variada em relação aos limites de tolerância a salinidade, dentro de uma mesma espécie pode haver variações entre genótipos nos quais os efeitos podem variar entre as fases de desenvolvimento (Neves et al. 2008).

Segundo Deuner et al. (2011), enquanto plantas halófitas são capazes de crescer em solos com concentrações de sais de até $20 \%$, as glicófitas, que envolvem a maioria das plantas cultivadas, têm seu crescimento inibido em concentrações da ordem de $0,3 \%$ a $0,5 \%$. Ainda de acordo com esse autor, a tolerância de plantas à salinidade é variável em função do ciclo fenológico ou do seu estádio de desenvolvimento. Os mecanismos de tolerância aos sais podem ser simples ou extremamente complexos. Os meios mais simples envolvem alteração de algumas vias bioquímicas e os mais complexos envolvem maior proteção do sistema respiratório e fotossintético, uso eficiente da água, manutenção da parede celular e cromossomos (Munns 1993, Munns 2002, Winicov 1998, Botella et al. 1994).

De acordo com Lima e Torres (2009), um dos métodos mais difundidos para determinação da sensibilidade das plantas a salinidade é a observação da germinação e desenvolvimento inicial em substratos salinos. Desta forma, objetivou-se com este trabalho verificar o efeito do estresse salino no desenvolvimento inicial e mobilização de reservas de plântulas de E. velutina submetidas a diferentes concentrações de solução de $\mathrm{NaCl}$ durante a germinação.

\section{Material e Métodos}

\section{Obtenção de sementes}

Foram utilizadas sementes de E. velutina provenientes de matrizes do Município de Jutaí (Lagoa Grande-PE), cujas coordenadas são W37¹8'03"S9052'9”, coletadas em outubro de 2009. As sementes foram beneficiadas manualmente, acondicionadas em saco plástico transparente $(0,15 \mathrm{~mm}$ de espessura) e mantidas em temperatura ambiente $\left(30^{\circ} \mathrm{C} \pm 5^{\circ} \mathrm{C}, 56 \pm 6 \%\right.$ UR) no Laboratório de Análise de Sementes da Embrapa Semiárido - LASESA, Petrolina -PE, local onde foram conduzidos os ensaios.

Previamente aos ensaios procedeu-se a escarificação mecânica do tegumento externo das sementes com o auxilio de uma mini retífica (Western R-40). Em seguida as sementes escarificadas foram submetidas à assepsia utilizando solução de hipoclorito de sódio comercial (2\%) durante 2 minutos sendo posteriormente lavadas em água destilada.

\section{Avaliação do crescimento de plântulas em diferentes condutividades elétricas}

Soluções de cloreto de sódio $(\mathrm{NaCl})$ em diferentes condutividades elétrica (CE) aferidas em 0, 4, 6, 8 e 12 dS.m ${ }^{-1}$ foram utilizadas na simulação do estresse salino. Para obtenção das soluções de $\mathrm{NaCl}$, seguiu-se a tabela proposta por Richards (1980), em que quantidades de sal foram diluídas em água destilada e, posteriormente, 
tiveram sua condutividade elétrica medida em condutivímetro "Digimed" modelo CD-21. O delineamento experimental utilizado foi o inteiramente casualizado, consistindo de cinco tratamentos (condutividades elétricas) e quatro repetições.

A avaliação do crescimento de plântulas foi feita de acordo com Nakagawa (1999). Quatro repetições de 10 sementes foram distribuídas sobre uma linha traçada no terço superior, no sentido longitudinal do papel germitest, umedecidos com soluções de $\mathrm{NaCl}$, em volume correspondente a 2,5 vezes o peso do papel. As sementes foram posicionadas com a extremidade da radícula para a parte inferior do papel. Foram confeccionados rolos semelhantes ao teste de germinação (Brasil 2009) e as quatro repetições (quatro rolos) foram agrupadas, vedados em saco plástico e colocados verticalmente, de maneira que o geotropismo se manifestasse naturalmente e facilitasse as avaliações das plântulas, no interior do germinador do tipo BOD ajustado à temperatura constante de $25^{\circ} \mathrm{C}$, fotoperíodo de $12 \mathrm{~h}$.

Após 16 dias, avaliou-se a germinação (plântulas formadas) e mediu-se o comprimento da parte aérea (CPA) e da raiz principal (CR). A partir dessas avaliações obteve-se um valor representado pela divisão do somatório dos comprimentos verificados, independentemente da classificação das plântulas, pelo número total de plântulas de cada repetição. Após a remoção dos cotilédones, a massa fresca da parte aérea (MFPA) e das raízes (MFR) das plântulas de cada repetição foi determinada. Após a pesagem inicial, estas foram acondicionadas em sacos de papel (Kraft) e colocadas para secar em estufa com circulação de ar a $70^{\circ} \mathrm{C}$, durante 48 horas. Após esse período, as amostras foram retiradas da estufa, colocadas em dessecador, e em seguida foram pesadas para determinação da massa seca total da parte aérea (MSPA) e raiz (MSR) das plântulas da repetição.

\section{Extração e análise de reservas}

Para esse procedimento foram utilizadas a matéria seca da parte aérea e raiz das plântulas submetidas às diferentes soluções de $\mathrm{NaCl}$ do teste de crescimento. A extração das reservas foi feita através da homogeneização de $0,2 \mathrm{~g}$ das amostras coletadas em $6 \mathrm{ml}$ de tampão fosfato de potássio 0,1 M pH 7,5 e centrifugadas a 10.000 $x g$ durante 20 min a $4^{\circ} \mathrm{C}$. A partir do extrato obtido foram determinados os teores de açúcares solúveis totaisAST (Morris 1948, Yemm e Willis 1954); açúcares redutores-AR (Miller 1959); sacarose- SAC (Passos 1996); proteínas solúveis totais- PT (Bradford 1976) e aminoácidos totais- AA Rosen (1957).

\section{Análise estatística}

Após análise de variância, foi realizada análise de regressão polinomial dos dados utilizando o programa Assistat (Silva 2006). Para o ajuste das equações de regressão polinomial, foi selecionado o modelo significativo que apresentou maior coeficiente de determinação. Foi estabelecido também o erro padrão da média para os dados cujas equações não se ajustaram (na).

\section{Resultados e Discussão}

A germinação das sementes de E. velutina não foi afetada pelo tratamento de simulação de estresse salino e, em todas as condutividades elétricas testadas, a germinação foi de 100\% (dados não apresentados). Por outro 
lado, os dados obtidos no teste de crescimento de plântulas indicam que todas as variáveis avaliadas em plântulas de 16 dias sofreram influência dos tratamentos salinos aplicados (Tabela 1).

Tabela 1 - Resumo da análise de variância do crescimento da parte aérea (CPA), crescimento da raiz (CR), massa fresca parte aérea (MFPA), massa fresca raiz (MFR), massa seca parte aérea (MSPA) e massa seca raiz (MSR) de plântulas de Erythrina velutina submetidas diferentes concentrações de solução de $\mathbf{N a C l}$.

\begin{tabular}{lcccccc}
\hline & \multicolumn{7}{c}{ Medidas de Vigor } \\
\cline { 2 - 7 } & CPA & CR & MFPA & MFR & MSPA & MSR \\
\hline F de Trat $\left(\mathbf{d S} . \mathbf{m}^{-1}\right)$ & $308,74^{*}$ & $30,07^{*}$ & $14,39^{*}$ & $11,22^{*}$ & $10,07^{*}$ & $10,70^{*}$ \\
C.V. (\%) & 7,39 & 14,38 & 22,76 & 21,37 & 16,33 & 15,02 \\
\hline
\end{tabular}

* significativo a $5 \%$ de probabilidade.

O desenvolvimento inicial das plântulas de mulungu (Figura 1) mostrou-se muito mais sensível ao o efeito do estresse salino quando comparado com a germinação. O maior crescimento de plântulas de mulungu foi observado na ausência de $\mathrm{NaCl}$, cuja condutividade elétrica (CE) apresentava $0 \mathrm{dS} \cdot \mathrm{m}^{-1}$. À medida que a CE aumentava no meio, houve diminuição linear do desenvolvimento das plântulas (Figura 1). À exceção das demais variáveis analisadas, a massa seca das raízes (MSR) não apresentou ajuste a nenhum modelo de regressão polinomial. Observou-se, ainda, que as maiores médias de MSR estão entre 0 e $4 \mathrm{dS} \cdot \mathrm{m}^{-1}$, sendo observada uma redução significativa à medida que a salinidade aumentou (Figura 1C).

O aumento da CE prejudicou o CPA com mais intensidade do que o CR das plântulas (Figura 1A). Observou-se ainda que dentro da tendência de redução linear dos resultados para MF e MS tanto na parte aérea como na raiz esse padrão se manteve (Figuras 1B e 1C).

Figura 1 - Medidas de A- crescimento da parte aérea (CPA) e crescimento da raiz (CR); B- massa fresca da parte aérea (MFPA) e massa da fresca raiz (MFR); C- massa seca da parte aérea (MSPA) e massa seca da raiz (MSR) de plântulas de E. velutina submetidas diferentes concentrações de solução de $\mathbf{N a C l}$.

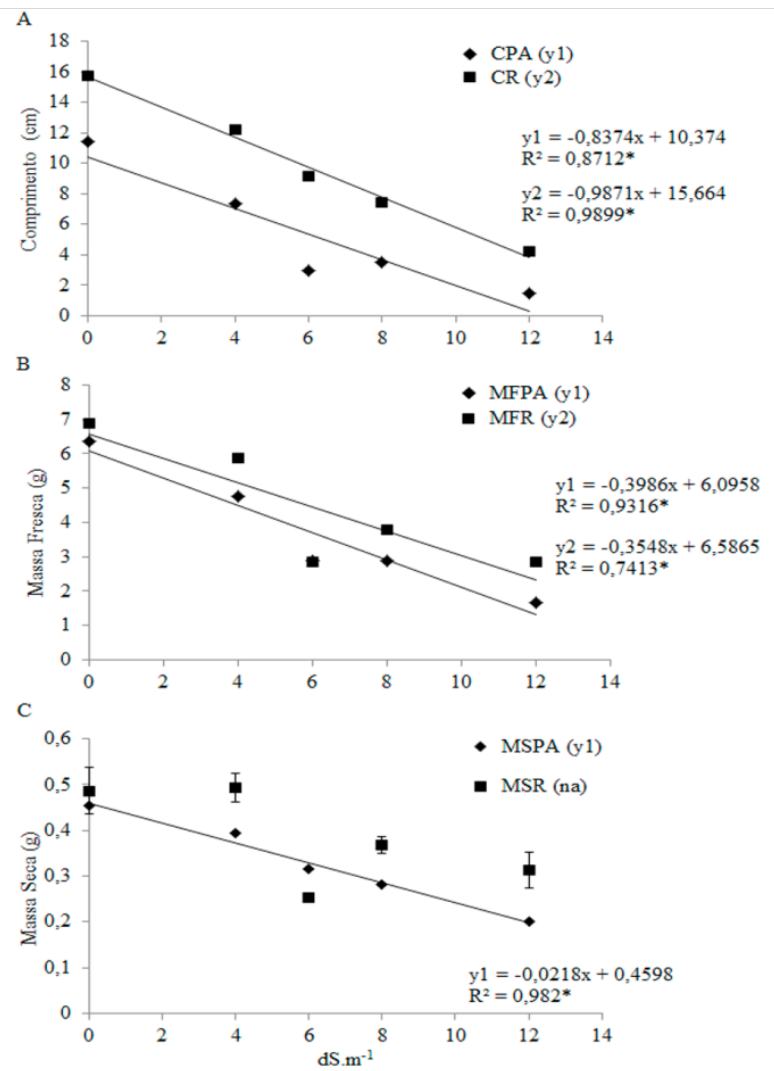


A adição de $\mathrm{NaCl}$ ao meio germinativo, e consequente aumento da $\mathrm{CE}$, reduziu a razão parte aérea/raiz das plântulas de E. velutina, indicando que o efeito da salinidade foi mais evidente na parte aérea que apresentaram uma redução de $(86,8 \%)$ no comprimento da parte aérea (CPA) do que nas raízes que apresentaram redução de $(73,46 \%)$ no comprimento da raiz principal (CR) (Figuras 1A e 2). Na CE de 6 dS.m ${ }^{-1}$ verificou-se uma redução no crescimento e investimento no acúmulo de reservas na parte aérea de plântulas das plântulas.

Figura 2 - Razão Parte aérea/Raiz das medidas de vigor (CPA) crescimento da parte aérea/ (R) crescimento da raiz; (MFPA) massa fresca da parte aérea/ (R) massa da fresca raiz; (MSPA) massa seca da parte aérea/ (R) massa seca da raiz de plântulas de E. velutina submetidas diferentes concentrações de solução de $\mathrm{NaCl}$.

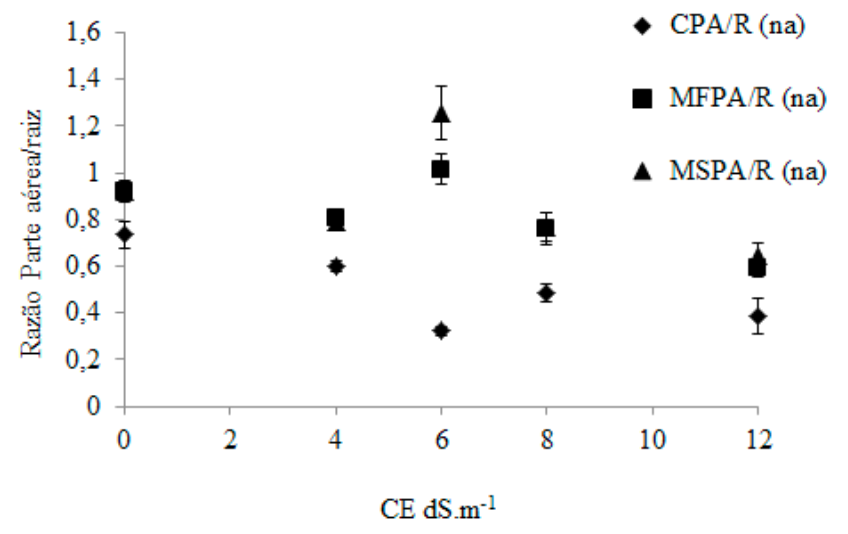

Além do mulungu, sementes de várias espécies da Caatinga, como Anadenanthera macrocarpa (Benth.) Brenan (Fabaceae), Aspidosperma pyrifolium Mart. (Apocynaceae) (Dantas et al. 2014) e Baubinia cheilantha (Bong) Stend. (Fabaceae) e Myracrodruon urundeuva Allemão (Anacardiaceae) (Oliveira et al. 2014), também apresentam alta tolerância ao estresse salino durante a germinação, devido à sua adaptação às condições climáticas extremas desse bioma, como altas temperaturas, secas frequentes e solos salinizados (Prado 2003).

O aumento da concentração de sais no substrato provoca déficit hídrico, desta forma a absorção de água pela semente é restrita, tornando inviável a sequência de eventos metabólicos que culminam para a emergência das plântulas (Ashraf e Foolad 2005, Flors et al. 2007, Custódio et al. 2009). As raízes suportam melhor a salinidade que a parte aérea, fenômeno este que pode estar associado a um ajustamento osmótico mais rápido e à perda de turgor mais lenta das raízes, quando comparadas com a parte aérea. Conseqüentemente, o crescimento radicular pode ser menos sensível que o crescimento da parte aérea à redução no potencial osmótico (Shalhevet et al. 1995), isto também se reflete na massa fresca e seca das plântulas, como foi observado em E. velutina (Figura 2).

Deuner et al. (2011), estudando o efeito da salinidade no crescimento inicial de plântulas de quatro genótipos de feijão-miúdo (Vigna unguiculata (L.) Walp - Fabaceae), verificou que com o aumento das concentrações salinas houve queda constante na produção de massa seca tanto na parte aérea quanto nas raízes, fato este observado no crescimento das plântulas de E. velutina neste estudo. Estes mesmos autores observaram que em concentrações menores e não tóxicas ocorreu menor redução no comprimento da parte aérea e produção de massa, no entanto, concentrações mais elevadas do estresse salino reduziu o crescimento das plântulas. Este fator é atribuído à diminuição na absorção de água, seguido por hidrólise limitada de reservas alimentares dos tecidos de armazenamento para o desenvolvimento do eixo embrionário das sementes (Khan e Panda 2008).

A menor redução do crescimento e acúmulo de massa sob condições moderadas de salinidade, encontrado nas plântulas de feijão-miúdo assim como nas plântulas de mulungu pode ser devido ao fato da ocorrência de um ajuste osmótico, em ocorrem incrementos no teor de proteínas solúveis e enzimas específicas, o que 
proporciona maior concentração de solutos (Deuner et al. 2011). A redução da matéria seca de plântulas em função da restrição hídrica se dá devido à menor velocidade dos processos fisiológicos e bioquímicos ou pela dificuldade de hidrólise e mobilização das reservas da semente (Bewley e Black 1994), o balanço osmótico é essencial para o crescimento dos vegetais em meio salino e qualquer falha neste balanço resultará em injúrias semelhantes aos da seca, como a perda de turgescência e a redução no crescimento, resultando em plantas atrofiadas, desidratadas e consequentemente levando à morte das células (Ashraf e Harris 2004).

As altas concentrações de sais no solo, além de reduzir o potencial hídrico do solo, podem provocar efeitos tóxicos nas plantas, causando distúrbios funcionais e injúrias no metabolismo. A redução no potencial hídrico dos tecidos causada pelo excesso de sais provoca restrição no crescimento uma vez que as taxas de alongamento e de divisão celular dependem diretamente do processo de extensão da parede celular (Ashraf e Harris 2004).

De modo geral, a salinidade promoveu nas plântulas de mulungu uma redução do teor de AR (Figura 3B), acompanhado de aumento de SAC (Figura 3C). Sementes de mulungu também apresentaram uma redução no teor de carboidratos livres em condições de estresse hídrico (Reis et al. 2012). A diminuição nos açúcares livres observada durante o período pré-protrusão radicular pode ter relação com a ativação do metabolismo inicial da semente, fornecendo energia para a germinação antes que os processos iniciais de mobilização de reservas possam ocorrer (Pritchard et al. 2002).

Os teores de AST nas plântulas se mantiveram num mesmo patamar em todos os tratamentos, com exceção para a parte aérea de plântulas que se desenvolveram em $6 \mathrm{dS} \cdot \mathrm{m}^{-1}$, que apresentaram uma maior concentração de AST (Figura 3A). Segundo Pontes et al. (2002), a utilização de amido ou de açúcares solúveis é variável, dependendo da espécie, podendo ocorrer durante a germinação ou no estádio de plântula. Durante a mobilização de reservas de sementes de garapa (Apuleia leiocarpa (Vogel) J.F.Macbr. - Fabaceae) esses autores não encontraram diferença significativa nos teores de açúcares solúveis durante o período de embebição.

Ocorreu uma redução linear dos AR na parte aérea de plântulas de mulungu, no entanto, nas raízes a redução foi mais acentuada até $6 \mathrm{dS} \cdot \mathrm{m}^{-1}$, a partir desta $\mathrm{CE}$ os teores de AR tornaram-se constantes. Em plântulas de cajueiro anão precoce, submetidas à salinidade não foram verificadas diferenças significativas na concentração de carboidratos em folhas e raízes de plântulas (Abreu et al. 2008). Em virtude da perda dos açúcares redutores sérios distúrbios podem ocorrer nas células, porque alguns desses açúcares são importantes intermediários na rota metabólica da fotossíntese e da respiração celular, enquanto outros são componentes estruturais de ácidos nucléicos, além de constituírem blocos básicos da construção de muitos outros carboidratos, incluindo amido e celulose (Salisbury e Ross 1992).

Os teores de AR verificados nas condutividades elétricas de 6 e $12 \mathrm{dS} \cdot \mathrm{m}^{-1}$ podem ser explicados quando se observa o efeito do aumento da condutividade elétrica induzindo o inverso nas concentrações de SAC (Figura 3C). Em halófitas, o acúmulo de carboidratos tem sido vastamente relatado como resposta à salinidade (Murakeozy et al. 2003). Assim, o acúmulo de SAC nas plântulas de mulungu (Figura 3C) promovido por essas CE podem indicar um ajuste para proteção e tolerância das plântulas à restrição hídrica e maior acúmulo de íons $\left(\mathrm{Na}^{+}\right.$e $\mathrm{Cl}^{-}$ ), por meio do acúmulo de osmólitos e aumento da atividade de enzimas antioxidantes (Ribeiro et al, 2014). As plantas recuperadas do estresse e as sementes de muitas plantas superiores são bons exemplos da ligação entre o acúmulo de carboidratos (sacarose em particular) e a aquisição da tolerância ao estresse (Hoekstra et al. 2001, Phillips et al. 2002). Esse desvio do metabolismo pode explicar também as menores medidas de crescimento encontradas nessas CEs (Figura 1). 
Figura 3 - Teores de Açúcares Solúveis Totais (A), Açúcares redutores (B) e Sacarose (C) ( $\mu$ mol $\left.\mathrm{g}^{-1} \mathrm{MF}\right)$ na parte aérea (PA) e raiz (RAIZ) de plântulas de E. velutina submetidas a diferentes concentrações de solução de $\mathrm{NaCl}$.
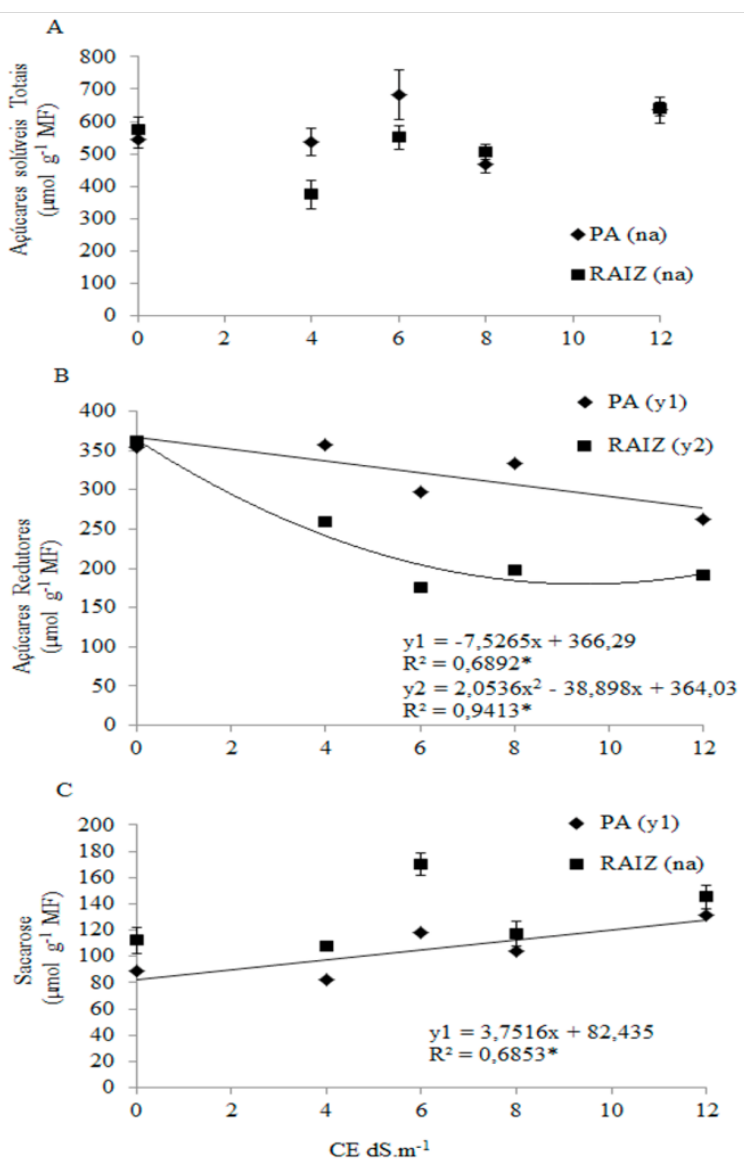

A toxicidade iônica pode ainda ocasionar o atraso da emergência das plântulas e da mobilização de reservas ou até diminuir a viabilidade das sementes, por afetar processos fisiológicos e metabólicos dos tecidos embrionários (Esteves e Suzuki 2008, Kumar et al. 2008, Munns e Tester 2008, Voigt et al. 2009). Naturalmente, o citoplasma acumula compostos de baixo peso molecular, os osmólitos, para adequar o balanço iônico nos vacúolos, que pouco intervêm nas reações bioquímicas habituais das plantas (Hasegawa et al. 2000, Zhifang e Loescher 2003). No entanto, sob estresse, estas substâncias resguardam estruturas e sustentam o balanço osmótico na planta (Hasegawa et al. 2000).

A salinidade promoveu um aumento de PT nas plântulas até $6 \mathrm{dS} \cdot \mathrm{m}^{-1}$ acompanhado de redução dos AA (Figuras 4A e 4B). Existem alguns estudos sobre o acúmulo de aminoácidos livres e outros compostos nitrogenados sob estresse salino. A maioria das plantas, frequentemente, acumula na forma de aminoácidos, amidas, proteínas e poliaminas, sendo este conteúdo variável entre as espécies (Gadallah 1999, Mansour 2000, Meloni et al. 2001). Estes compostos atuam no ajuste osmótico, proteção de macromoléculas celulares, estocagem de nutrientes, manutenção do pH celular, desintoxicação de células e minimização dos efeitos das espécies reativas de oxigênio (Ashraf e Harris 2004).

A partir de $6 \mathrm{dS} . \mathrm{m}^{-1}$ verificou-se um decréscimo dos teores de PT (Figura 4A) e um aumento nos teores de AA em $8 \mathrm{dS} \cdot \mathrm{m}^{-1}$ com posterior redução em $12 \mathrm{dS} \cdot \mathrm{m}^{-1}$ (Figura 4B). Durante o efeito da salinidade, determinados processos são danificados, tais como: síntese de proteínas, metabolismo de lipídios e fotossíntese. Em uma intensificação do estresse, uma das respostas iniciais é a redução da expansão da superfície foliar (Wang e Nil 2000). 
Figura 4 - Teores de Proteínas Solúveis (A) e Aminoácidos Totais (B) ( $\mu \mathrm{mol} \mathrm{g}^{-1}$ MF) na parte aérea (PA) e raiz (RAIZ) de plântulas de E. velutina submetidas a diferentes concentrações de solução de $\mathrm{NaCl}$.

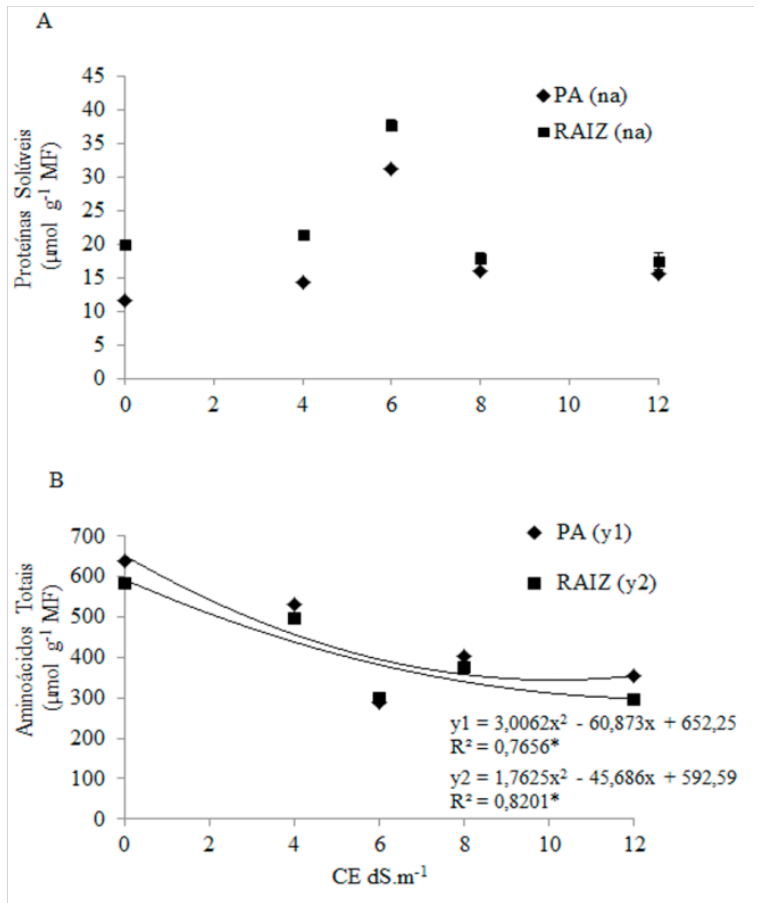

A redução no comprimento de plântulas se deve a mudanças na turgescência celular em função da diminuição da síntese de proteínas em condições de déficit hídrico (Dell’Aquilla 1992). O primeiro efeito mensurável do estresse hídrico é uma diminuição no crescimento causada pela redução da expansão celular que necessita de potencial de turgor adequado (Taiz e Zeiger 2006). O aumento da salinidade provavelmente inibiu a atividade proteásica durante o estabelecimento da plântula em 8 e $12 \mathrm{dS} \cdot \mathrm{m}^{-1}$, afetando provavelmente a mobilização protéica nos cotilédones e o desenvolvimento da plântula de E. velutina.

A inibição do crescimento inicial de E. velutina ocasionada pela salinidade se deve tanto ao efeito osmótico, ou seja, à seca fisiológica produzida, como ao efeito tóxico, resultante da concentração de íons no protoplasma (Tobe et al. 2000). Além disso, a toxicidade iônica pode causar redução no crescimento das plantas sob estresse salino por desencadear danos às membranas e redução da atividade de enzimas hidrolíticas (Essa 2008).

\section{Conclusões}

Pelos resultados obtidos neste estudo, pode-se concluir que: (1) a restrição hídrica e a toxidez promovida pelocloreto de sódio $(\mathrm{NaCl})$ provocou uma desaceleração dos processos fisiológicos e bioquímicos durante a germinação, afetando negativamente o crescimento de plântulas de E. velutina. (2) Plântulas de E. velutina provavelmente não suportam crescer em solos com potencial acima de $6 \mathrm{dS} . \mathrm{m}^{-1} \mathrm{CE}$, tornando uma limitação para essa espécie florestal em ambientes que apresentam estas condições.

\section{Agradecimentos}

Os autores gostariam de agradecer ao CNPq, FACEPE e CAPES pelo suporte financeiro para realização 
deste estudo.

\section{REFERÊNCIAS}

Abreu CEB, Prisco JT, Nogueira ARC, Bezerra MA, Lacerda CF e Gomes-Filho E. 2008. Physiological and biochemical changes occurring in dwarf-cashew subjected to salt stress. Brazilian Journal of Plant Physiology, 20(2): 105-118.

Ashraf M e Foolad MR. 2005. Pre-sowing seed treatment-a shotgun approach to improve germination growth and crop yield under saline and none-saline conditions. Advances in Agronomy, 88: 223-271.

Ashraf M e Harris PJC. 2004. Potential biochemical indicators of salinity tolerance in plants. Plant Science, 166(1): 3-16.

Bewley JD e Black M. 1994. Seeds: physiology of development and germination. New York and London: Plenum Press, 445p.

Botella MA, Quesada MA, Kononowicz A, Bressan RA, Hasegawa PM e Valpuesta V. 1994. Characterization and in situ localization of a salt-induced tomato peroxidase messenger-RNA. Plant Molecular Biology, 25: 105-114.

Bradford MM. 1976. A rapid and sensitive method for the quantitation of microgram quantities of protein utilizing the principle of protein-dye binding. Analytical Biochemistry, 72(1/2): 248-254.

Braga LF, Souza MP e Almeida TA. 2009. Germinação de sementes de Enterolobium schomburgkii (Benth.) submetidas a estresse salino e aplicação de poliamina. Revista Brasileira de Plantas Medicinais, 11(1): 63-70.

Brasil. 2009. Ministério da Agricultura, Pecuária e Abastecimento. Regras para análise de sementes. Secretaria de Defesa da Agropecuária. Brasília, 395 p.

Carvalho PER. 2008. Mulungu (Erythrina velutina). Circular Técnica 160, $1^{\circ}$ Ed. Embrapa Florestas, Colombo, PR, Dez, 8 p.

Carvalho NM e Nakagawa J. 2012. Sementes: Ciência, tecnologia e produção. 4. ed. Jaboticabal: UNESP, $590 \mathrm{p}$.

Chaves MM, Flexas J e Pinheiro C. 2009. Photosynthesis under drought and salt stress: regulation mechanisms from whole plant to cell. Annals of Botany, 103(4): 551-560.

Custódio CC, Machado Neto NB, Moreno ELC e Vuolo BG. 2009. Water submersion of bean seeds in the vigour evaluation. Revista Brasileira de Ciências Agrárias, 4(3): 261-266.

Dantas BF, Ribeiro RC, Matias JR e Araújo GGL. 2014. Germinative metabolism of Caatinga forest species in biosaline agriculture. Journal of Seed Science, 36(2): 194-203.

Dell'Aquila A. 1992. Water uptake and protein synthesis in germinating wheat embryos under osmotic stress of 
polyethylene glycol. Annals of Botany, 69(2): 167-171.

Deuner C, Maia MS, Deuner S, Almeida AS e Meneghelloet GE. 2011. Viabilidade e atividade antioxidante de sementes de genótipos de feijão-miúdo submetidos ao estresse salino. Revista Brasileira de Sementes, 33(4): $711-720$.

Essa TA. 2008. Effect of salinity stress on growth and nutrient composition of three soybean (Glicine max L. Merrill) cultivars. Journal of Agronomy Crop Science, 188: 86-93.

Esteves BS e Suzuki MS. 2008. Efeito da salinidade sobre as plantas. Oecologia Australis, 12(4). 662-679.

Flors V, Paradís M, García-Andrade J, Cerezo M, Bosch GC e Pilar GAP. 2007. A tolerant behavior in saltsensitive tomato plants can be mimicked by chemical stimuli. Plant Signaling \& Behavior, 2(1): 50-57.

Flowers TJ, Troke PF e Yeo AR. 1977. The mechanism of salt tolerance in halophytes. Annual Review of Plant Physiology, 28: 89-121.

Góis VA, Torres SB e Pereira RA. 2008. Germinação de sementes de maxixe submetidas a estresse salino. Revista Caatinga, 21(4): 64-67.

Greenway H e Munns R. 1980. Mechanisms of salt tolerance in nonhalophytes. Annual Review of Plant Physiology, 31: 149-190.

Hoekstra FA, Golovina EA e Buitink J. 2001. Mechanisms of plant desiccation tolerance. Trends in Plant Science, 6: 431-438.

Khan MH e Panda SK. 2008. Alterations in root lipid peroxidation and antioxidative responses in two Rice cultivars under NaCl-salinity stress. Acta Physiologiae Plantarum, 30(1): 81-89.

Kumar N, Pamidimarri SDVN, Kaur M, Boricha G e Reddy MP. 2008. Effects of $\mathrm{NaCl}$ on growth, íon accumulation, protein, proline contents and antioxidant enzymes activity in callus cultures of Jatropha curcas. Biologia, 63(3): 378-382.

Lima BG e Torres SB. 2009. Estresses hídrico e salino na germinação de sementes de Zizypphus joaz̧eiro Mart. (Rhamnaceae). Revista Caatinga, 22(4): 93-99.

Lorenzi H e Matos FJA. 2002. Plantas Medicinais no Brasil: nativas e exóticas cultivadas. São Paulo: Instituto Plantarum de Estudos da Flora Ltda.

Mayer AM e Poljakoff-Mayber A. 1989. The Germination of Seeds. Great Britain: Pergamom Press, 270p.

Miller GL. 1959. Use of dinitrosalicilic acid reagent for determination of reducing sugar. Analytical Chemistry, 31(3): 426-428.

Mistura C, Santos AEO, Orika ONO, Rodrigues JD, Almeida MB e Araújo AJB. 2011. Germinação e desenvolvimento de plântulas de cunhã em função da salinidade. Revista Brasileira de Saúde e Produção Animal, 12(2): 306-317. 
Morris DL. 1948. Quantitative determination of carbohydrates with Drywood's anthrone reagent. Science, 107(2775): 254-255.

Munns R. 1993. Physiological processes limiting plant growth in saline soils: some dogmas and hypotheses. Plant, Cell and Environment, 16(1): 15-24.

Munns R. 2002. Comparative physiology of salt and water stress. Plant, Cell and Environment, 25(2): 239250 .

Munns R. 2005. Genes and salt tolerance: bringing them together. New Phytologist, 167(3): 645-663.

Munns R e Tester M. 2008. Mechanism of salinity tolerance. Annual Review of Plant Biology, 59: 651-681.

Murakeözy EP, Naqy Z, Duhazé C, Bouchereau A e Tuba Z. 2003. Seasonal changes in the levels of compatible osmolytes in three halophytic species of inland saline vegetation in Hungary. Journal of Plant Physiology, 160(4): 395-401.

Nakagawa J. 1999. Testes de vigor baseados no desempenho das plântulas. In: Krzyzanowski FC, Vieira RD e França-Neto JB. (Eds), Vigor de sementes: conceitos e testes. Londrina: ABRATES, 218p.

Neves ALR, Guimarães FRVA, Lacerda CF, Silva FB e Silva FLB. 2008. Tamanho e composição mineral de sementes de feijão-de-corda irrigado com água salina. Revista Ciência Agronômica, 39(4): 569-574.

Oliveira GM, Matias JR, Ribeiro RC e Dantas BF. 2014. Germinação de sementes de aroeira-do-sertão (Myracrodruon urundeuva Fr. All.) e mororó (Baubinia cheilantha (Bong) Stend.) em diferentes condutividades elétricas. Revista Sodebras, 9: 70.

Passos LP. 1996. Métodos analíticos e laboratoriais em fisiologia vegetal. Coronel Pacheco: EmbrapaCNPGL, 223p.

Phillips JR, Oliver MJ e Bartels D. 2002. Molecular genetics of desiccation and tolerant systems. In: CAB International. Desiccation and survival in plants: drying without dying. Washington, 319-341.

Pontes CA, Borges EEL e Soares CPB. 2002. Mobilização de reservas em sementes de Apuleia leiocarpa (Vogel) J.F. Macbr. (garapa) durante a embebição. Revista Árvore, 26(5): 593-601.

Prado DE. 2003. As caatingas da América do Sul. Pp. 3-73. In: Leal IR, Tabarelli M e Silva JMC. (Eds.). Ecologia e conservação da Caatinga. Recife, Editora Universitária, Universidade Federal de Pernambuco.

Pritchard SL, Charlton WL, Baker A e Graham IA. 2002. Germination and storage reserve mobilization are regulated independently in Arabidopsis. The Plant Journal, 31(5): 639-647.

Ribeiro RC, Matias JR, Pelacani CR e Dantas BF. 2014. Activity of antioxidant enzymes and proline accumulation in Erythrina velutina Willd. seeds subjected to abiotic stresses during germination. Journal of Seed Science, 36(2): 231-239.

Ribeiro-Reis RC, Dantas BF e Pelacani CR. 2012. Mobilization of reserves and germination of seeds of 
Erythrina velutina Willd. (Leguminosae - Papilionoideae) under different osmotic potentials. Revista Brasileira de Sementes, 34(4): 580-588.

Richards LA. 1980. Suelos Salinos y Sodicos. Instituto Nacional de Investigaciones Agrícolas. México, 171p. Rosen HA. 1957. A modified ninhydrin calorimetric analysis for amino acids. Archives of Biochemistry and Biophysics, 67(1): 10-15.

Sairam RK e Tyagi A. 2004. Physiology and molecular biology of salinity stress tolerance in plants. Current Science, 86(3): 407-421.

Salisbury FB e Ross CW. 1992. Plant physiology. Calfornia: Wadsworth, Inc. 682p.

Shalhevet J, Huck MG e Schroeder BP. 1995. Root and shoot growth responses to salinity in maize and soybean. Agronomy Journal, 87(3): 512-516.

Silva FASE, Azevedo CAV. 2006. A New Version of The Assistat-Statistical Assistance Software. In: World Congress On Computers In Agriculture, 4: Anais. American Society of Agricultural and Biological Engineers, p.393-396.

Silva MBR, Viégas RA, Dantas-Neto J e Farias SAR. 2009. Estresse salino em plantas da espécie florestal sabiá. Caminhos da Geografia, 10(30): 120-127.

Taiz L e Zeiger E. 2006. Fisiologia vegetal. Porto Alegre: Artmed, 719p.

Tobe K, Li X e Omasa K. 2000. Seed germination and radicle growth of a halophyte, Kalidium caspicum (Chenopodiaceae). Annals of Botany, 85(3): 391-396.

Viégas RA, Silveira JAG, Lima Junior AR, Queiroz JE e Fausto MJM. 2001. Effects of NaCl-salinity on growth and inorganic solute accumulation in young cashew plants. Revista Brasileira de Engenharia Agrícola e Ambiental, 5(2): 216-222.

Voigt EL, Almeida TD, Chagásicos RM, Ponte LFA, Viégas RA e Silveira JAG. 2009. Source-sink regulation of cotyledonary reserve mobilization during cashew (Anacardium occidentale) seedling establishment under $\mathrm{NaCl}$ salinity. Journal of Plant Physiology, 166(1): 80-89.

Wang Y e Nil N. 2000. Changes in chlorophyll, ribulose bisphosphate carboxylase-oxygenase, glycine betaine content, photosynthesis and transpiration in Amaranthus tricolor leaves during salt stress. The Journal of Horticultural Science and Biotechnology, 75(6): 623-627.

Winicov I. 1998. New molecular approaches to improving salt tolerance in crop plants. Annals of Botany, 82(6): 703-710.

Yemm EW e Willis AJ. 1954. The estimation of carbohydrates in plants extracts by anthrone. Biochemical Journal, 57(3): 508-514.

Zhifang G e Loescher WH. 2003. Expression of a celery mannose 6-phosphate reductase in Arabidopsis thaliana 
enhances salt tolerance and induces biosynthesis of both mannitol and a glucosyl-mannitol dimmer. Plant Cell \& Environment, 26: 275-283. 